\title{
The Role of Macroeconomic Variables in Sovereign Risk
}

\author{
George Zairis \\ Fund Accounting Analyst, Luxembourg \\ E-mail: georgezairis21@gmail.com \\ Antonios Zairis (Corresponding Author) \\ Neapolis Pafos University, Greece \\ E-mail:antoniszairis@gmail.com
}

Received: October 28, 2019 Accepted: December 23, 2019 Published: January 10, 2020

doi:10.5296/ieb.v6i1.16221

URL: https://doi.org/10.5296/ieb.v6i1.16221

\begin{abstract}
The sovereign debt market has gathered a lot of attention post the global financial recession therefore it is very important to study how the countries of the eurozone countries can be shielded from all internal and external risks. This can be achieved by examining the macroeconomic determinants of the sovereign risk. Based on the results of the panel regression, it becomes evident which financial indicators are contributing to the sovereign risk. In terms of the stochastic properties, when homogeneity is assumed among the cross-sectional units, all the variables appeared to be level stationary except for the total government bond yield. However, when heterogeneity is assumed among the countries, variables such total government bond yield, GDS as a percentage of GDP, total credit to private sector, employment as a ratio to total GDP, and bank credit are level none stationary. Consequently, these findings will help identify the variables that can be used to approximate the movement of the government bond yield.
\end{abstract}

Keywords: Sovereign risk, Macroeconomic variables, Economic crisis, Investment environment

\section{Introduction}

It is an undeniable fact that the sovereign debt market has gathered a lot of attention post the global financial recession. Prior to 2008, the trading in the credit market was mainly based on 
instruments of the private sector, such as securitisation instruments and corporate credit risk (Shin, 2012). However, the collapse of one of the biggest investment bank in the US, Lehman Brothers, in 2008, emphasised on the requirement of reassessing the default risk of sovereigns of developed economies (Panetta et al., 2009). As a result, the public sector deficits showed a sharp rise due to the bank bailouts and other stimulus packages. For instance, the fiscal burden of bank support measures in the UK was estimated at $44 \%$ of UK GDP (Panetta et al., 2009). As the euro is one of the strongest and more powerful currencies worldwide (and the second most traded currency behind the U.S. dollar), it is extremely important to study how the euro-zone countries can be shielded and well protected from all internal and external risks. This can be achieved by examining the macroeconomic determinants of the sovereign risk.

Therefore, the main purpose of this work is to identify the macroeconomic determinants of sovereign risk. The research sample consists of the 19 euro-zone, covering the period between 1999 (the year which the countries participating in the European Monetary Union adopted the euro as their common currency) and 2016. It presents a review of the existing literature and highlights the relation of our findings with the existing empirical evidence. This is followed by the sample selection and the methodology. It then focuses on the results of panel regression, containing detailed discussion of the research findings. The final section presents a summary of the key findings, the conclusion and recommendations for policies and further research.

\subsection{The Role of Macroeconomic Variables in Sovereign Risk}

The interaction between macroeconomic variables and sovereign risk was analysed by Badr and El-khadrawi (2016). Sovereign credit ratings give information about the country's ability to meet its financial obligations. They also investigated the impact of investment environment on sovereign bond yield and described the important factors affecting sovereign risk. Sovereign ratings impact the solvency of a country as well. Higher ratings provide the flexibility to access global markets. The paper presents an overview of credit ratings, the importance of their functioning and an insight of the influence of risk rating on macroeconomic factors. Their research points the link between risk and sovereign bond yields. In the security exchange market, risk premia denotes the minimum rate of return on assets. The ratings assigned to assets are included in factors in the calculation of risk premia and pricing of assets. The risk factors associated with assets can be defined as sovereign risk, country risk, currency exchange risk, convertibility risk etc. The paper points out the differences between sovereign risk and country risk. EMBI+ index is the most crucial factor in the calculation of sovereign risk premia. They also investigated the process of rating agencies of assessment of sovereign risk. The authors used a discretionary approach based on quantitative methods.

Canuto, Santos and Porto (2004) focused on examining factors of sovereign risk and the relation between these variables and ratings. Their study results with a list of small variables responsible for differences between risk ratings of countries. The variables are per capita income, inflation, economic growth, current account receipts ratio, government debt and fiscal receipts etc. The paper makes suggestions to improve these determinants to ear high sovereign ratings of emerging countries. The improvement of these variables will help the 
countries in achieving overall good macroeconomic health. The rating agencies focus on assessing the capacity of a government to service its debt before maturity. The ratings can be defined as the estimation of sovereign risk but they do not provide any information about bilateral credits or debts. Risk ratings are available on the public domain that leads to reducing the uncertainties associated with the risk involved in government bonds. The investors consider the risk ratings as the actual indicators of the probability of default. Sovereign risk can also be defined as a subtype of credit risk and it is very important for emerging market firms. The research shows that macroeconomic factors impact the entire yield curve.

Finally, Matsumtra and Valentim (2009) used a simple macro to yield process and the bilateral model for the investigation of macroeconomic determinants. Sovereign risk and country risk are defined as two different concepts. Country risk is broader as compared to sovereign risk. Country risk encompasses the financial assets of a country. They define five determinants that help in pushing the rating of a particular firm like the amount of debt, assets held abroad, supply networks and integration with global production. The sovereign rating is important as it has the direct bearing on assets prices. The sovereign rating also helps in determining the potential buyer base. They found various factors affecting sovereign rating including GDP growth, inflation, fiscal balance, reserves, current account balance and public domestic debt. The sovereign rating depends on both qualitative and quantitative variables. Current account deficit also plays an important role in determining the rank of rating and is the result of the deficit in trade structure. The results provide important information for investors and policymakers. The emerging countries should focus on reducing the current account deficit to increase their international position. The government should also focus on using on reducing the fiscal deficit.

\section{Data and Methodology}

In this section, the study describes the methodology used to conclude the initial objectives. This includes the sampling techniques, sample selection, sources of data and definition of variables. Other aspects are the estimation techniques, which include the stochastic properties of the series using Levin, Lin, and Chu (1992) and Im, Pesaran and Smith (1999) as well as the co-integration test using the procedure introduced by Kao (1999) and Pedroni (1997, 1999 and 2000).

\subsection{Data}

\subsubsection{Sample Selection and Sources of Data}

In this research, a non-random sample of 19 countries is chosen. Non-probability sampling technique is used to conclude the sample of the 19 eurozone countries i.e. the monetary union of European Union. The countries included in this work are the following: Austria, Belgium, France, Spain, Cyprus, Estonia, Finland, Germany, Greece, Ireland, Italy, Latvia, Lithuania, Luxembourg, Netherlands, Portugal, Slovenia, Estonia, and Slovakia. The main purpose of this paper is to analyse the determinants of sovereign bond yield and the indicators affecting country risk. The research aims to evaluate the effects of various macroeconomic factors on bond yields. Long-Term Government Bond Yield is used as a proxy of country risk and therefore, is the dependent variables, while various macroeconomic indicators used as 
independent variables. The data for the dependent and independent variable were collected from the World Bank Data and the DataStream. The dataset used for analysis was constructed using two databases from World Bank, i.e. The World Development Indicators (WDI) and the Global Financial Development Database (GFDD).

More specifically, the macroeconomic indicators which were collected from the World Development Indicators (WDI) of the World Bank Data was the Economic growth (GDP), Inflation (CPI), Domestic credit to private sector (DCPC), Employment (EPR), National income(ANNI) and Foreign Direct Investment (FDI). The indicators collected from the Global Financial Development Database (GFDD) of the World Bank Data, was the Bank Credit to deposits (BCD) and the Banking system stability (BZ-score). Finally, the data which was collected from the DataStream was the Total Return index (SR) and the dependent variable of the model, the Long-Term Government Bond Yield.

\subsubsection{Sample Time Period}

The basis to choose the most appropriate time period was to include most recent years and to ensure that the length of the time period was long enough for the topic. An appropriate selection of time period is one of the key elements to conclude to reliable results. In this work, the sample time period is from 1999 to 2016.1999 was the starting year of the euro and that is the reason why our time period starts from this specific year. During this period many counties in the European Union became part of the eurozone and moreover there were periods of financial distress especially for some specific countries like Greece, Ireland or Portugal. The determinants of different periods are expected to be different because of the different macroeconomic situations in different phases of the countries.

\subsubsection{Panel Data}

Panel data, also known as longitudinal data, refers to the pooling of cross-sectional observations of firms, households, countries or others over several time periods (Baltagi, 2005). The form of the panel data based firstly in the selection of several individuals or other samples such as countries in this specific thesis and then followed by several time periods. Consequently, each sample has multiple observations representing different times, which briefly means that panel keeps the same entities and measures some features about them over some time periods (Brooks, 2002). In this case, the selected sample is the 19 countries of the eurozone (EMU). As for the time period, 1999 to 2016 is selected, with a frequency of once a year. As a result, there are 324 observations used in the paper in total, all of which together form the panel data set.

As with any statistical method, panel data have both advantages and disadvantages over cross-sectional or time series data sets. As Baltagi (2005) focuses on, it is an undeniable fact that panel data conclude to more informative data, which is very important and means more variability, less collinearity among variables, more efficiency and finally more degrees of freedom. Secondly, panel data are more appropriate to identify and measure effects that are difficult to detect in pure cross-section or pure time-series data. Thirdly, panel data can overcome the limitations of time series and cross-sectional data in which the first method does not deal with different entities and the second one does not assume the different effect of independent variables in different periods of time. Finally, the use of panel contributes to a 
more efficient control to the impact of omitted variables (Hsiao, 2014).

On the other hand, panel data can face problems such as distortions of measurement errors or problems associated with design and data collection. Moreover, short time series dimension can also face problems (Baltagi, 2005).It is possible that there is heterogeneity across different samples and over time that is not observed in the model apparently. Consequently, more accurate outcomes can be generated from panel data analysis.

\subsection{Methodology}

\subsubsection{Stochastic Properties of the Series}

This part of the analysis focuses on examining the mean, variance and covariance of the sample. It is expected that the mean and variance should be constant over two given period of time and the covariance for two sub-samples to be zero. This is the concept of stationarity. When a variable is stationary, it is expected that it will be stable over a long period of time hence it will give an ability to construct a stable model. However, when the variable contained a unit root, the use of it for the impact analysis will produce estimates that are spurious which cannot be relied uponfor policy formulation and forecasting.

To test the stochastic properties for the pooled series, various testing procedures were developed, and this can be categorised into two groups; that is, the homogeneous and heterogeneous. While the former assumed the absence of any difference among the cross-sectional units; that is all the countries have the same economic characteristics and hence can be used as a single entity. However, the latter group assumes differences in terms of the cross-sectional units. For the purpose of this study, one in each of the homogeneous and heterogeneous groups was employed. Therefore, the study used Levin, Lin and Chu (1992) for the homogeneous group while Im, Pesaran, and Shin (1996) were used for the former group. To understand the Levin, Lin, and Chu (1992) test well, consider the following relationship:

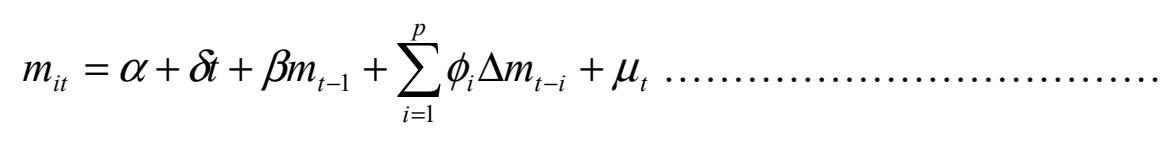

Where $\mathrm{m}$ is the time series under consideration which was collected over period $\mathrm{t}$ for all ith cross sections, from the above model, two assumptions were made in its deterministic component; that is, the presence of homogeneous intercept and trend coefficients. By this, we assumed that the economic characteristics of the countries over time and on average remain the same. Now, to test the hypotheses of unit root versus stationarity, two procedures are used. The first involves assessing the coefficient of the autoregressive component (lag value of the dependent variable), and since the variable is in level form, it is expected to be less than zero for stationarity evidence and greater than zero otherwise. The second procedure involves estimating the test statistic of the variable. In this case, the calculations estimated is compared with a critical value at given level of significance, and the decision favours stationarity if the estimated value is higher than the critical value others the evidence is rejected in favour of the unit root. The lag values of the difference of the dependent variable was introduced in the model to correct the serial correlation problem identified in the use of random walk models to check stationarity of time-series data. For a detailed discussion on the time series version, see 
Dickey (1976) and Fuller (1988).

However, the major drawback of the above test is the homogeneous assumption among the cross-sectional units. To address the problem, Im, Pesaran, and Smith (1996) developed an alternative test of unit root that assumed heterogeneous cross-sectional units. This will aid us to see if it exists, a situation whereby for a given series, part of the cross-section will be stationary while other will not. To understand Im, Pesaran, and Smith (1996) better, consider the following equation:

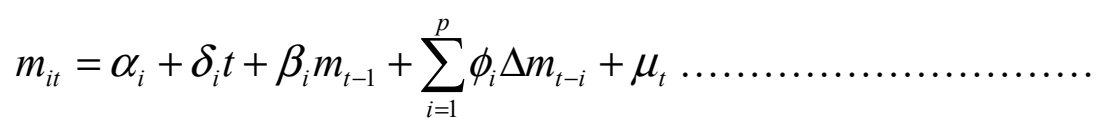

In this test, dynamic heterogeneity was used, where all the variables were allowed to vary across the cross-sectional units. The testing procedure remains the same as the one described in Levin, Lin and Chu (1992) procedure which was discussed above.

\subsubsection{Co-integration Test}

Having described the stochastic properties of the series, the outcome involved two possibilities. In the first case, the series can be level stationary (implying that they can be used directly for the impact analysis) hence there is no need to test for the cointegrating relationship between the variables. However, in the second case, all or some of the variables may be level non-stationary. Under this condition, a possible co-integrating relation is examined between the combinations of two or more variables. This is to examine whether the combination of two or more known stationary variables will produce an error that is stationary or not. This type of test was popular in the time series modelling approach but was extended by the proponent of the panel analysis also. The early development of the panel co-integration test includes Kao (1999) Mcoskey and Kao (1997), Pedroni (1997, 1999 and 2000) among others.

Just like the stationary test, the cointegration tests were also developed in two groups; that is, the homogeneous and heterogeneous. For the former group, the cross-sectional units are assumed to be the same, while is allowed to vary in the latter group. For the purpose of this study, Kao (1999) and Pedroni (1997, 1999 and 2000) test are used. This will give us evidence in favour of the two groups as identified above. The justification for the choice of these two tests is to have a robust integration and co-integration evidence. The Kao (1999) test is a residual based test consider for example the following regression and its auxiliary form:

$$
m_{i t}=\alpha_{i}+\delta_{i} t+\beta_{i} n_{i t}+\mu_{i}
$$

Where $m$ is the dependent variable and $n$ is explanatory variable or vectors. Just as in the stochastic properties, here, slope and intercept are assumed as the deterministic components of the relation. From the model in equation 2.3, the procedure for the test is to generate the residual of the equation and subject it to the unit root test using either of the methods described above. If the residual is stationary, it means that the series $\mathrm{m}$ and $\mathrm{n}$ are co-integrated while if the residual contains a unit root, it is in favour of the unit root. The resultant auxiliary regression of 2.3 is given as: 


$$
\mu_{i t}=\alpha_{i}+\phi_{i} \mu_{i t-1}+v_{i}
$$

From the above equation, if the first lag value of the coefficient is statistically significant or is greater than the tabulated value, it means series $\mathrm{m}$ and $\mathrm{n}$ are co-integrated otherwise they are not. Just like the Levin, Lin, and Chu (1992), the Kao (1999) test also belongs to the homogeneous group. Hence, it has a problem and it is not reliable. To resolve this issue, Pedroni (1997, 1999 and 2000) proposed a residual based test that assumed heterogeneity among the cross-sectional units. He proposes seven different tests for the parametric and non-parametric as while as group and panel for the cross-sections. To understand the test, consider the following equations:

$$
m_{i t}=\alpha_{i}+\delta_{i} t+\beta_{i} n_{i t}+\mu_{i}
$$

Where $\mathrm{m}$ is the dependent variable and $\mathrm{n}$ is explanatory variable or vectors. Just as in the stochastic properties, here, we also assumed slope and intercept as the deterministic components of the relation. From the model in equation 2.5, the procedure for the test is to generate the residual of the equation and subject it to the unit root test using either of the methods described above. If the residual is stationary, it means that the series $m$ and $n$ are co-integrated while if the residual contains a unit root, it is in favour of the unit root. The resultant auxiliary regression of 2.5 is given as:

$$
\mu_{i t}=\alpha_{i}+\phi_{i} \mu_{i t-1}+v_{i}
$$

From the above, if the first lag value of the coefficient is statistically significant or is greater than the tabulated value, it means series $m$ and $n$ are co-integrated otherwise they are not.

The test is synonymous with the KPSS of univariate time series analysis. Unlike Kao (1999) that assumed the null of no cointegration and alternative of cointegration, here, in the case of Pedroni (1997, 1999 and 2000) the null is of co-integration, and the alternative is of no cointegration. Therefore, the study used the two tests to ensure the robustness of the co-integrating evidence.

\subsubsection{Fixed and Random Effects Panel Data Models}

Having determined the integration and cointegration properties of the series, the next step is to present the model for the impact analysis. This will aid us to see the impact of the explanatory on the dependent variables. To achieve this, a static panel regression model was necessary with fixed and random effect models were used. To understand the models, consider the equation below:

$$
m_{i t}=\alpha_{i}+\delta t+\beta_{i} n_{t}+\phi_{i} w_{t}+\mu_{i}
$$

Where $\mathrm{n}$ and $\mathrm{w}$ are the explanatory variables and $\mathrm{m}$ is the dependent variable. The model in equation 2.7 is the fixed effect model, where it is assumed that the intercept varies across different cross-sectional units. In another word, it's assumed that there exist economic, cultural and social differences among the countries. We also assumed complete static heterogeneity in the model. An alternative to this model is the random effect assumption where the intercept is assumed to be the same across all the countries in the cross-sectional 
units, and if there is any different among the cross-section, it should be random in nature. Consider the following equation:

$$
m_{i t}=\alpha+\delta t+\beta_{i} n_{t}+\phi_{i} w_{t}+w_{i}
$$

Where $\alpha_{i}$ is assumed to be $w_{i}=\alpha+\mu_{i}$ which derived the difference if there is any? Therefore, for the purpose of this work, the models in equations 2.7and 2.8 are used to study the interaction between the variables.

\section{Result Presentation and Analysis}

\subsection{Result Presentation}

In this section, the estimated outputs and the discussion of the results is presented. It includes the summary statistics of the variables, the stochastic properties and the co-integration analysis. For the impact model, the fixed and random panel data regression models were estimated.

Table 1. Summary of the descriptive statistics

\begin{tabular}{llllll}
\hline Variables & Obs. & Mean & Std. Dev. & Min & Max \\
\hline Total Bond Yield & 342 & 4.46 & 2.42 & -0.18 & 22.5 \\
GDP growth & 342 & 2.32 & 3.88 & -14.81 & 25.55 \\
GDS\%GDP & 342 & 24.87 & 8.64 & 8.33 & 54.68 \\
Domestic Credit & 342 & 92.39 & 40.31 & 16.96 & 253.26 \\
Emp. to Pop & 342 & 52.55 & 4.97 & 37.74 & 64.72 \\
National income & 342 & 2.05 & 4.67 & 25.89 & 451.71 \\
FDI & 342 & 13.17 & 43.23 & -58.32 & 451.71 \\
CPI & 342 & 93.69 & 12.27 & 57.65 & 112.15 \\
Bank Credit & 342 & 117.09 & 39.96 & 17.79 & 257.32 \\
Bank Z core & 342 & 11.72 & 7.13 & 0.02 & 37.76 \\
Total return index & 342 & 6417.18 & 8409.80 & 82.89 & 54077.27 \\
\hline
\end{tabular}

Source: STATA output.

Table 1 presents the summary of the descriptive statistics which includes: the mean which shows the average value of the relationship over the sample horizon, the standard deviation which shows the volatility between the average, and finally the minimum as well as the maximum values of the observations. The total bond for the 19 selected countries has an average yield of $4.46 \%$ over the sample horizon, the standard deviation of the bond yield for the same period stood at $2.42 \%$ the minimum, and maximum yields were found to be $-0.18 \%$ and $22.5 \%$ respectively. The evidence for the GDP growth rate shows a mean value of $2.32 \%$ with a standard deviation of $3.88 \%$. The result further shows that the countries have 
experienced a minimum productivity growth rate of $-14.81 \%$ with a maximum value of $25.55 \%$. Here, it is important to focus in two facts. Firstly, the standard deviation of the productivity growth rate exceeds the average value; this is some because the sample has pooled many countries including those that face an economic slowdown in recent years. Secondly, the minimum productivity growth shows a negative value which implies that some of the countries experienced a recession over the sample period.

Furthermore, the percentage of gross domestic saving to GDP for the countries shows has a mean value of $24.87 \%$ with standard deviation of $8.64 \%$, the minimum, and maximum value for the variable stand at $8.33 \%$ and $54.68 \%$ respectively. The evidence for the domestic credit to the private sector which represents the total credit extended by both public and private sector to business over a given period of time, the evidence shows an average value of $\$ 92.39$ billion with a standard deviation of $\$ 40.31$ billion. The minimum and maximum credit to the private sector over the period stood at $\$ 16.96$ and $\$ 253.26$ billion respectively. This evidence is not surprising because most if not all of these countries have well developed financial market and the credit risk is very minimal hence both public and private sector within and outside these economies have higher confidence in extending loans and advances to private sectors of these countries. See, for example, the works of Bernoth, Hagen and Schuknecht (2006), Boyd and Smith (2000), and Taylor (2012) among others.

In addition, the result for the ratio of total employment to the population of these countries, the result shows that on the average about $92.39 \%$ are employed in another word, it is only $7 \%$ of the population which is unemployed. The volatility of the ratio of employment to population is $40.31 \%$. This is because of the economic slowdown some of the countries have faced during the study period. The maximum and minimum employment rate during the period was $37.74 \%$ and $64.74 \%$ respectively. The employment figure as shown by the above result is disturbing as it shows that for the entire sample, they have a minimum of $63 \%$ unemployment. However, this is not surprising given the presence of countries such as Greece who have faced a severe economic crisis in the recent years.

As for the national income variable, which is the end product of the GDP and it is the difference between the monetary values of the total production of the countries' citizen minus the monetary value of the foreigner's production within the 19 countries of the sample after taking away the issue of depreciation. The descriptive statistic evidence shows that over the entire sample horizon, the average national income for the countries stood at $\$ 2.05$ billion with a standard deviation of $\$ 4.67$. The minimum and maximum value for the national income stood at $\$ 25.89$ billion and $\$ 451.71$ billion respectively. The evidence for the Foreign Direct Investment (FDI) which represent the total foreign productive investment that comes into the sampled countries shows a mean value of $\$ 13.17$ billion with a standard deviation of $\$ 43.23$ billion respectively. The minimum and maximum FDI inflow over the sample horizon stood at $\$ 58.32$ billion and $\$ 451.71$ billion respectively.

The consumer price index which represents the persistent increase in the general price level over a given period. The evidence shows that prices have increased over the sample period to $93.63 \%$ on the average and the prices fluctuation was estimated to be $12.27 \%$. The minimum and maximum price index for the selected 19 European countries over the sample horizon stood at $57.65 \%$ and $112.15 \%$ respectively. This is not surprising due to the inclusion of 
countries like Greece who had experienced hyperinflation between 2014 and 2016. Furthermore, the total bank credit, which represents the total liability of deposit money bank with the central bank(s) European Central Bank (ECB) the evidence shows that the variables have a mean of $\$ 117.09$ billion with a standard deviation of $\$ 39.96$ billion. The minimum and maximum total liabilities for the banking sector over the entire sample period were $\$ 17.79$ billion and $\$ 257.32$ billion respectively. The commercial banks Z-score for the sampled countries reveals an average value of 11.72 with a standard deviation of 7.13 , the minimum and maximum values of 0.02 and 37.76 respectively. Finally, the total return index score shows for the companies located in the selected countries shows that over the sample horizon, the return was on the average $\$ 6417.18$ billion with a variation of $\$ 8409.80$ billion respectively. The minimum and maximum return during the period stood at $\$ 82.89$ billion and $\$ 54077.27$ billion respectively. Here, it is important to note that there is no available data for total return index scores for Belgium, Cyprus, Estonia, Malta, Slovakia, however, in order not to leave the space empty a median value of the observations were used therefore the result for this variable should be taken with caution.

\subsection{Panel Unit Root and Co-integration Test}

Now, having seen the nature of the summary statistic for the variables under consideration by this study, the next task is to carry out a proper examination of the determinant of the government bond yield for the selected European countries. To succeed that, the study as explained in the methodology chapter carried out a comprehensive panel data analysis. This involves the estimation of the panel stochastic properties of the series using the homogeneous and heterogeneous procedure. The study went further to present the co-integration result using Kao (1997) and Pedroni (1997, 1999 and 2000). The order of integration and that of co-integration enables us to estimate the fixed and random effects panel data regression model for the sample period. The evidence is presented in the tables below.

The literature on the development of stochastic properties has evolved over time just like the time series counterpart. The first effort has to do with the work of Levin, Lin, and Chu (1992) who tries to analyse the mean, variances, and covariance of a given data with a view to find if the data is time-dependent otherwise the presence of time-invariant characteristics in the data. The Levin, Lin, and Chu (1992) stationarity test are based on the assumption that the cross-sectional units are homogeneous. Put differently; the test assumes that there is no difference in terms of the economic, social and other characteristics between the sampled countries. Levin, Lin, and Chu (1992) test were based on the extension of the ADF unit root which is popularly used in time series analysis. Therefore, the decision regarding the stochastic properties is taken a base on t-statistic. The assumption here about the null hypothesis is that that there exists a unit root in a given variable for across all the countries in the sample and this is tested against the alternative hypothesis of stationarity. The decision is reached by comparing the calculated t-statistic with the corresponding critical values at a given level of significance which in most cases use to be $5 \%$. The decision rule is to accept the null if the computed t-statistic is higher than the tabulated one at a given level of significance. Alternatively, a decision can be reached regarding the stochastic properties of the series using probability value. For this, the null of a unit root is accepted if the probability value is greater than 0.05 (if $5 \%$ level of significance is assumed) otherwise if the probability 
value is less than or equals to 0.05 , the evidence is in favour of the alternative hypothesis of the stationary variable. For the sake of this study, both t-statistic and probability values were used, and the evidence is presented in Table 2 below.

Table 2. Panel stochastic properties

\begin{tabular}{|c|c|c|c|c|}
\hline \multirow[t]{2}{*}{ Variables } & \multicolumn{2}{|c|}{ LLC (1992) } & \multicolumn{2}{|c|}{ IPS (1997) } \\
\hline & t-stat. & Prob. value & t-bar & Prob. value \\
\hline Total govt. bond & 1.73 & 0.95 & -0.45 & \\
\hline GDP growth & -7.97 & 0.00 & -2.86 & \\
\hline GDSofGDP & -2.61 & 0.004 & -1.51 & \\
\hline Credit to private & -3.06 & 0.001 & -1.42 & \\
\hline Emp. To Pop. & -1.87 & 0.03 & -0.93 & \\
\hline Net national growth & -6.13 & 0.00 & -3.12 & \\
\hline FDI & -7.19 & 0.00 & -3.26 & \\
\hline CPI & -5.84 & 0.00 & -2.09 & \\
\hline Bank Credit & -4.08 & 0.00 & -1.18 & \\
\hline Bank Z-Score & -1.98 & 0.02 & -1.90 & \\
\hline Total ret index & -2.18 & 0.01 & NA & \\
\hline
\end{tabular}

$-2.000,-1.860$ and -1.780 represent $1 \%, 5 \%$ and $10 \%$ critical values for IPS (1997) test

Source: STATA output.

The evidence in Table 2 presents the result of the Im, Pesaran, and Smith (1999) testing procedure. At this point, it is important to note that the test doesn't report probability values. Therefore, our decision will be based on the t-statistic otherwise known as t-bar. However, the decision rule is as explained under the Levin, Lin, and Chu (1992) test. The tabulated critical values at $1 \%, 5 \%$ and $10 \%$ level of significance are presented in the table below. Here, we compare the t-bar values with the calculated critical values to make the statistical decision. For the government bond yield, the calculated t-bar is less than the critical values at all level of significance implying that the variable is none stationary. Therefore, the stochastic properties for this variable remain the same under the two-testing procedure. Hence the assumption of homogeneity or heterogeneity of the cross-sectional units doesn't alter the conclusion.

From the result presented in Table 2, we can notice the test statistics and the probability values for all the variables used in this study. This is done to ensure the robustness of the estimates. From the evidence, we can see that total government bond yield is level non-stationary because the calculated t-statistic is greater than the critical value at $5 \%$ level of significance. Also, the probability value for the government bond yield is 0.95 or $95 \%$ which implies the acceptance of the null hypothesis that the variable is level none stationary. 
However, for all the rest of the variables, the t-statistics is greater than the critical value at 5\% level of significant implying that they are level stationery.

To ensure the robustness of the evidence, we look at the probability values of the variables. From the evidence presented in Table 1, the Levin, Lin, and Chu (1992) probability values for all the variables except total government bond yield are less than 0.05 . Going by our rule of thumb of accepting the alternative hypothesis, then the evidence for the rest of the variables is in favour of the alternative hypothesis of the stationary variable. Therefore, the conclusion in terms of the stochastic properties of the variables under consideration using Levin, Lin, and Chu (1992) testing procedure is that all the variables used by this study are level stationery except total government bond yield that appeared level stationery.

At this point, having seen the stochastic properties of the series, the study went further to re-examine the same evidence using the different testing procedure. Here, the essence is to ensure the robustness of the conclusion we have made under the Levin, Lin, and Chu (1992) testing procedure. To achieve this, we use the Im, Pesaran and Smith (1999) testing procedure. However, unlike in the case of Levin, Lin, and Chu (1992) that assumes the presence of homogeneous cross-sectional units, the Im, Pesaran and Smith (1999) assumed the existence of heterogeneous cross-sectional units. This test is also an extension of the ADF unit root type test hence the appropriate test statistic is t-value. However, the Im, Pesaran and Smith (1999) have come with two sets of test statistics; that is, the t-bar and adjusted t-bar. The assumption under this test is that the autoregressive component of the equation is heterogeneous, that is, each country has different economic, social and political characteristics unlike the Lin and Chu (1992) that assumes homogeneous autoregressive component in the ADF type equation. For a detailed discussion on the difference between the Lin and Chu (1992) and the Im, Pesaran and Smith (1999) it would be useful to examine the methodology section.

The result as presented in the table shows that we can not reject the null hypothesis of level any stationary variable for total government bond, GDS as a ratio of GDP, total credit to private sector, the ratio of employment to population and bank credit. However, the evidence for GDP growth rate, net national income growth, foreign direct investment, CPI and bank z-score are level stationary at either $5 \%$ or $1 \%$ level of significance. In the case of the Im, Pesaran, and Smith (1999) for total bank return index present no result. From these results, we can see that there are quite some numbers of disagreements in terms of the conclusions reached by the study regarding the two tests. Firstly, in the case of Levin, Lin, and Chu (1992), all the variables appeared stationary except total government bond yield whereas the Im, Pesaran, and Smith (1999) show that most of these variables are level non-stationary. Secondly, even for the variables that both appeared significant in both the tests, the level of significance is higher in Levin, Lin, and Chu (1992) than under the IPS (1992) procedure. Therefore, for the purpose of this study, we accept the evidence as presented by the Im, Pesaran, and Smith (1999) for two reasons. Firstly, while the IPS assumes heterogeneity of the cross-sectional units, looking closely at the sampled countries one will agree that the selected countries; although belong to Europe and are part of the developed nations, have differences in terms of economic size and other geographical characteristics hence the Im, Pesaran, and Smith (1999) provides more approximation to the series than Levin, Lin, and Chu (1992) test. 


\section{Macrothink}

Now having seen the stochastic evidence properties, there are three possibilities. Firstly, if all the variables appeared to be level stationary, under this case, the study can go ahead to estimate the impact model using either static (panel regression model) or dynamic (Panel VAR) approaches. Secondly, if the variables are level non-stationary, the study can assess whether the combination of two or more variable will produce a stochastic process that is stationary. This has to do with checking the long run relationship between the variables and when it exists the impact model can be estimated using panel error correction mechanism in case of the single equation or vector error correction model in case of multiple equations. Finally, if there is the absence of co-integration among the variables, then the study can examine the evidence through a different system (panel regression at the difference for single equation or difference panel VAR multi-variables equation. Now, since we accept the Im, Pesaran, andSmith (1999) evidence, there is the need to estimate the co-integration relation between the variables.

Table 3. Panel co-integration test

\begin{tabular}{llllc}
\hline & \multicolumn{2}{l}{ Kao } \\
$(1997)$ & & $\begin{array}{l}\text { Pedroni } \\
(1997,1999,2000)\end{array}$ \\
\hline ADF & Stat & Prob. & Stat. & Prob. \\
$\begin{array}{l}\text { GBY/ GDPG, FDI, CPI, EMP/PoP, bank credit, } \\
\text { bank z-score, credit to the private sector }\end{array}$ & 0.81 & 0.25 & 2.24 & 0.07 \\
\hline
\end{tabular}

Source: STATA output.

The evidence in Table 3 presents the cointegration evidence based on Kao (1997) and Pedroni (1997, 1999 and 2000) procedure. As we have seen, the Kao (1997) belongs to the homogenous co-integration test while Pedroni (1997, 1999 and 2000) belong to the heterogeneous group. Here, under the Kao (1997) testing procedure, the null hypothesis of no co-integration is tested against an alternative of co-integration. However, the Pedroni (1997, 1999 and 2000) tests the null of co-integration against an alternative of non-co-integration. From the evidence presented in Table 3, the result shows that the evidence is in favour of the null hypothesis in the case of Kao (1997) test and alternative hypothesis in the case of Pedroni (1997, 1999 and 2000). This evidence implies the absence of a long-run relationship between the variables and is consistent with the two-modelling procedure.

Having determined the order of in-integration and co-integration, the next task is to present the impact model. To do that, both fixed and random effect modelling approaches were used, and the choice of these models is in line with what economic theory predicts. The evidence is presented in Table 4 below.

\section{Panel Impact Model}

The result in Table 4 presents the estimates of panel regression model based fixed and random effect assumptions. The differences between these two modelling approaches were explained in the methodology chapter. To see the determinants of government bond yield for 
the selected countries, the study uses some series of explanatory variables which were found to be the determinants of bond yield for different economies. For the purpose of this study, variables such as GDP growth rate, the ratio of GDS to GDP, the total credit extended to the private sector, the ratio of employment to total population, national income, foreign direct investment, bank z-score, CPI, and bank credit.

Table 4. Panel Impact model using total government bond yield as the dependent variable

\begin{tabular}{|c|c|c|c|c|c|c|c|c|}
\hline \multirow[t]{2}{*}{ Variables } & \multicolumn{4}{|c|}{ Fixed Effect Model } & \multicolumn{4}{|c|}{ Random Effect Model } \\
\hline & Coeff. & $\begin{array}{l}\text { Std } \\
\text { error }\end{array}$ & t-stat & Prob. & Coeff. & $\begin{array}{l}\text { Std } \\
\text { error }\end{array}$ & Z-stat & Prob. \\
\hline GDP Growth & $-0.221^{*}$ & 0.044 & -4.97 & 0.00 & $-0.21^{*}$ & 0.04 & -4.82 & 0.00 \\
\hline GDSofGDP & 0.067 & 0.047 & 1.41 & 0.15 & 0.032 & 0.03 & 1.05 & 0.29 \\
\hline Credit to Priv. & 0.005 & 0.005 & 0.90 & 0.36 & 0.004 & 0.004 & 1.01 & 0.31 \\
\hline Emp. To pop. & $-0.25^{*}$ & 0.043 & -5.82 & 0.00 & $-0.20^{*}$ & 0037 & -5.53 & 0.00 \\
\hline $\begin{array}{l}\text { National } \\
\text { Income }\end{array}$ & -0.002 & 0.033 & -0.07 & 0.94 & -0.001 & 0.033 & -0.05 & 0.96 \\
\hline FDI & 0.002 & 0.004 & 0.64 & 0.52 & 0.003 & 0.004 & 0.83 & 0.40 \\
\hline Bank Z-score & 0.053 & 0.094 & 0.56 & 0.57 & 0.009 & 0.089 & 0.11 & 0.91 \\
\hline CPI & $-0.08^{*}$ & 0.008 & -9.83 & 0.00 & $-0.08^{*}$ & 0.008 & -9.96 & 0.00 \\
\hline Bank Credit & $0.02^{*}$ & 0.004 & 4.25 & 0.00 & $0.020 *$ & 0.004 & 4.79 & 0.00 \\
\hline Constant & $21.68^{*}$ & 2.31 & 9.37 & 0.00 & $20.13^{*}$ & 2.00 & 10.05 & 0.00 \\
\hline R-square & 0.41 & & & & 0.41 & & & \\
\hline Chi-Squ./F-st & 26.58 & & & 0.00 & 210.40 & & & 0.00 \\
\hline
\end{tabular}

$*, * *$, and $* * *$ implies significance at $1 \%, 5 \%$ and $10 \%$ levels respectively.

Source: STATA output.

For the fixed effect model, the sign shows that GDP growth rate, employment as a ratio of population, national income, and inflation are negatively related to government bond yield. This implies that an increase in any one of these variables will lead to a decrease in government bond yield and vice versa. The sign for inflation is consistent with the theoretical expectation because it is expected that an increase in the prices of goods and services will lead to a decrease in government bond yield and vice versa. However, the sign for economic growth, national income and ratio of employment to population are inconsistent with the conventional wisdom; therefore, for these variables, they are expected to be positive. The result also proves that GDS as a ratio of GDP credit to private sector, FDI, and bank z-score are positively related to government bond yield. This implies that an increase in any of these variables will lead to an increase in these variables. The positive sign is in line with the theoretical expectation. In terms of the magnitude of the relation, the evidence shows that all 
the coefficients have a magnitude that is less than unity except for the intercept which represents the average value of the relationship that has a magnitude of 21.68. This means that even if all the variables were to be held constant, the average government bond yield for these countries would be $21.68 \%$.

In terms of the significance of the variables, three set of statistics were used; these are, the t-statistic for the fixed effect model and the z-statistic for the random effect model. Other statistics that will help in explaining the significance of the variables include the standard error and the probability values. In the case of $\mathrm{Z}$ or $\mathrm{T}$ statistic, the statistical decision is reached regarding the significance of the variable or otherwise by comparing the calculated test statistic with the critical value(s) at a given level of significance. For the standard error, the decision rule is to accept that a variable is statistically significant if the magnitude of the coefficient is greater than the standard error otherwise the evidence is in favour of the insignificant variable. For the probability value, the decision regarding the significance of a variable is reached if probability value is less than or equals to 0.05 otherwise when the probability value is greater than 0.05 the evidence is in favour of the insignificant variable.

To assess the significance of the variables, the study used all the three sets of statistics. Using the standard error, the result shows that under the fixed effect modelling assumption, GDP growth rate, the ratio of employment to population, and CPI have coefficients that are greater than the standard error which based on the already stated rule of thumb these variables are considered to be statistically significant in explaining government bond yield among the selected European countries. For the rest of the variables, the magnitude of the standard error is greater than the critical value implying that they are statistically insignificant. Going by the t-statistic, we can also confirm that the critical values at 5\% significance level are less than the calculated statistics for GDP growth rate, the ratio of employment to population, CPI and bank credit. However, for the ratio of GDS to GDP, credit to private sector, national income, FDI, and bank z-score, their calculated value is less than the critical values hence the evidence is in favour of the null hypothesis of the insignificant variable.

For the random effect model, the sign shows that GDP growth rate, employment as a ratio of population and inflation is negatively related to government bond yield. This implies that an increase in any one of these variables will lead to a decrease in government bond yield and vice versa. The sign for inflation is consistent with the theoretical expectation, because it is expected that an increase in the prices of goods and services will lead to decrease in government bond yield and vice versa, this is the same evidence we got under the fixed effect modelling assumption only that national income was found to be negative also under fixed effect model and positive under the random effect models. However, the sign for economic growth and the ratio of employment to population are inconsistent with the conventional wisdom; therefore, for these variables, they are expected to be positive.

The result further shows that GDS as a ratio of GDP credit to private sector, FDI, national income and bank z-score are positively related to government bond yield. This implies that an increase in any of these variables will lead to an increase in the government bond yield. The positive sign is in line with the theoretical expectation. In terms of the magnitude of the relation, the evidence shows that all the coefficients have a magnitude that is less than unity except for the intercept which represents the average value of the relationship that has a 
magnitude of 20.13. This means that even if all the variables were to be held constant, the average government bond yield for these countries would be $20.13 \%$.

To assess the significance of the variables, the study used all the three sets of statistics as discussed under the random effect modelling approach. Using the standard error, the result using the random effect model effect modelling assumption shows that, GDP growth rate, the ratio of employment to population, Bank Credit and CPI have coefficients that are greater than the standard error which based on the already stated rule of thumb these variables are considered to be statistically significant in explaining government bond yield among the selected European countries, the significance for this variables is consistent with what the study found under the fixed modelling approach only that bank credit appeared statistically significant. For the rest of the variables, the magnitude of the standard error is greater than the critical value implying that they are statistically insignificant. Going by the t-statistic, we can also confirm that the critical values at 5\% significance level are less than the calculated statistics for GDP growth rate, the ratio of employment to population, CPI and bank credit. However, for the ratio of GDS to GDP, credit to private sector, national income, FDI, and bank z-score, their calculated value is less than the critical values hence the evidence is in favour of the null hypothesis of the insignificant variable.

\subsection{Robustness of the Models}

To validate the fixed effect model, two sets of statistics were used. These are the R-square, and the Chi-square or F-statistic in case of fixed and random effect model respectively. The $\mathrm{R}$-square which is the coefficient of determination is usedto see the goodness of fit of the regression model. It has a value ranging from 0 to 1 in which the former implies all the points lie off the regression model while the latter implies that all the relationship points are on the regression model. However, the values between these ranges signify difference level of determination. From the evidence in Table 4, we can see that the R-square is about 0.41 or $41 \%$ this implies that $41 \%$ of the points are on the regression line. Based on this, we can accept the fact that the fixed effect regression line used in this study is the good one. This is because the rest of the regression lines have a lesser value of R-square. To see if the entire set of explanatory variables used in explaining the dependent variables are adequate, the study uses chi-square statistic. The evidence shows a value of 26.58 which is higher than the tabulated value at 5\% significance level; this implies that the variables used by this study are adequate in explaining the determinant of government bond yield for the selected countries.

To validate the Random model, two sets of test statistics just as in the fixed effect model. These statistics are the r-square and the F-statistics. The R-square shows a value of 0.41 which is $41 \%$ is just like the fixed effect model and it shows that the line is the best among all the competing regression lines. To see if the explanatory variables are adequate in explaining the dependent variable, the F-statistic shows a value of 210.40 which is greater than $1 \%$ tabulated critical value. Therefore, the variables are best in describing the determinants of government bond yield for the selected countries.

\section{Conclusion}

The evidence in terms of the stochastic properties of the series using the Levin, Lin and Chu (1992) shows that all the variables are level stationary except for the total government bond 


\section{MInstitute ${ }^{\text {Macrothink }}$}

yield. However, the Im, Pesaran and Smith (1999) test shows that total government bond yield, GDS as a percentage of GDP, total credit to private sector, employment as a ratio to total GDP, and bank credit are level none stationary. Whereas, the result of the total return index shows no result, and this is due to the unavailability of data for some countries. This finding is consistent with the work of Min (1998), Pagano and Thadden (2004), Pesaran, Shin and Smith (1999) among others. Evidence of the Levin, Lin and Chu (1992) procedure except for total government bond that appeared level none stationary in both tests. Moreover, the impact model could not be carried out without assessing the multivariate stochastic properties of the series. Here, there are three options; first, if the variables appeared to be related in the long run, the impact model can be carried out using panel VECM. Second, if there is no long-run relationship among the variables, the impact model can be carried out using panel differenced VAR. Finally, if the variables are level stationary, the impact model can be carried out using panel VAR.

A model was constructed using government bond yield as the dependent variable with all the other variables as explanatory variables to see whether the combination of the variables produces common stochastic properties among the series. This test was carried out using Kao (1997) and Pedroni (1997, 1999 and 2000). The former test assumes homogeneity among the series while the latter test assumes heterogeneity just like in the Levin, Lin and Chu (1992) and the Im, Pesaran and Smith (1999). The result shows that there is no long-run relationship between total government bond yield and the series used as explanatory variables. However, the Pedroni procedure shows the presence of common stochastic properties among the series.

To determine the multivariate stochastic properties of the series, the assumption regarding the relationship between the cross-sectional units is very important as the evidence between the tests that assume homogeneity among the cross-sectional units varies with those test that assumes heterogeneity. This evidence is consistent in both the univariate and multivariate stochastic properties of the series. Therefore, the evidence varies with the assumption made regarding the variables.

The study used both fixed and random effect model to ensure the robustness of the estimates and the evidence shows that quantitatively there is no difference in terms of the result between the fixed and random effect modelling approaches. For example, the result shows that GDP growth rate, the ratio of employment to population, CPI inflation and bank credit are statistically significant at $1 \%$ level. This finding is consistent with both the fixed and random effect models. In terms of the sign of the relationship, the result shows that GDP growth rate, the ratio of employment to population, national income and CPI are negatively related with government bond yield while the rest of the variables are positively related, and the magnitude of the relationship is less than unity for all the variables. This result is consistent with both the fixed and random effect models.

In conclusion, we can accept that in terms of the stochastic properties, when homogeneity is assumed among the cross-sectional units, all the variables appeared to be level stationary except for the total government bond yield. However, when heterogeneity is assumed among the countries, variables such total government bond yield, GDS as a percentage of GDP, total credit to private sector, employment as a ratio to total GDP, and bank credit are level none stationary. Therefore, from the stochastic properties evidence, the study accepts the null 
hypothesis of the none stationary.

Therefore, the result in terms of the multivariate stochastic properties (co-integration) of the series is that when homogeneity among the cross section is assumed, the evidence shows the absence of co-integration, whereas in the case of heterogeneity, the evidence shows the existence of the long-run relationship among the variables. Therefore, the presence of co-integration or otherwise depends on the assumption made regarding the relationship between the cross-sectional units (homogeneity or heterogeneity).

Furthermore, in terms of the impact model the results show that the sets of variables used for this study are adequate in explaining the relationship between the variables. The evidence shows that the GDP growth rate, the ratio of employment to population, CPI inflation and bank credit are statistically significant in explaining the relationship between the variables. Therefore, these variables can be used to approximate the movement of government bond yield.

Given the findings, the study urges the need for modern economic integration that is inclusive. This will help in reducing the growth asymmetries among the EU economies. When there is a general policy for all European Union members, given their differences in terms of the stage of development than there is every tendency that the policy will benefit the bigger economies more than, the smaller ones. In terms of government bond yield, when there is a positive shock hitting the economies, it tends to have more benefit for the bigger economies which make the cost of their credit lower than that of the smaller economies. However, when there is a negative shock, the cost of credit will be higher for the smaller economies and lesser for the bigger economies. Therefore, a reform within the EU is needed to make the magnitude of the impact of the shock to have the same magnitude on the countries. In addition, the respective economies should introduce policies that ensure output growth in their countries. This is because an increased output implies a reduction in unemployment and thereby leads to a decline in the cost of borrowing for a country. There is also the need for proper monetary policy conduct and implementation by the European central bank. This will help top reventany inflation threat that may likely hit the economies. As we have seen the presence of a negative relationship between government bond yield and inflation, inflation is identified as an important factor to take into consideration.

\section{References}

Badr, O. M., \& El-khadrawi, A. F. (2016). Macroeconomic Variables, Government Effectiveness and Sovereign Credit Rating: A Case of Egypt. Applied Economics and Finance, 3(4), 2332-7294. https://doi.org/10.11114/aef.v3i4.1632

Baltagi, B. H. (2005). Econometric Analysis of Panel Data (3rd ed.). John Wiley \& Sons Inc., New York.

Bernoth, K., von Hagen, J., \& Schuknecht, L. (2006). Sovereign Risk Premiums in the European Government Bond Market, Discussion Paper Series of SFB/TR 15 Governance and the Efficiency of Economic Systems, Free University of Berlin, Humboldt University of Berlin, University of Bonn, University of Mannheim, University of Munich.

Canuto, O., Santos, P. F., \& Porto, P. C. (2004). Macroeconomics and Sovereign Risk Ratings. Worldbank. 


\section{Macrothink}

Issues in Economics and Business

ISSN 2377-2301 2020, Vol. 6, No. 1

Hsiao, C. (2014). Analysis of Panel Data (3rd ed.). Cambridge University Press, Cambridge. https://doi.org/10.1017/CBO9781139839327

Im, K., Pesaran, H., \& Shin, Y. (1997). Testing for Unit Roots in Heterogeneous Panels. Discussion Paper, University of Cambridge.

Kao, C. (1999). Spurious Regression and Residual-Based Tests for Cointegration in Panel Data. Journal of Econometrics, 90, 1-44. https://doi.org/10.1016/S0304-4076(98)00023-2

Levin, A., \& Lin, C. F. (1992). Unit Root Test in Panel Data: Asymptotic and Finite Sample Properties. University of California at San Diego, Discussion Paper.

Levin, A., Lin, C. F., \& Chu, C. J. (2002). Unit root tests in panel data: asymptotic and finite-sample properties. Journal of Econometrics, 108(1), 1-24. https://doi.org/10.1016/ S0304-4076(01)00098-7

Matsumtra, M., \& Valentim, J. (2009). The role of macroeconomic variables in sovereign risk.

McCoskey, S., \& Kao, C. (1998). A residual-based test of the null of cointegration in panel data. Econometric Reviews, 17(1), 57-84. https://doi.org/10.1080/07474939808800403

Pedroni, P. (1997). Fully modified OLS for heterogeneous cointegrated panels and the case of purchasing power parity. Department of Economics, Indiana University, Mimeo.

Pedroni, P. (1999). Critical values for cointegration tests in heterogeneous panels with multiple regressors. Oxford Bulletin of Economics and Statistics, Special Issue, 61, 653-670. https://doi.org/10.1111/1468-0084.61.s1.14

Pedroni, P. (2000). Fully modified OLS for heterogeneous cointegrated panels. Advances in Econometrics, 15, 93-130. https://doi.org/10.1016/S0731-9053(00)15004-2

Taylor, M. (2012). The antinomies of 'financial inclusion': debt, distress and the workings of Indian microfinance. Journal of Agrarian Change, 12(4), 601-610. https://doi.org/10.1111/ j.1471-0366.2012.00377.x

\section{Copyright Disclaimer}

Copyright for this article is retained by the author(s), with first publication rights granted to the journal. This is an open-access article distributed under the terms and conditions of the Creative Commons Attribution license (http://creativecommons.org/licenses/by/3.0/). 